\title{
Teaching Mode Research of Flipped Classroom Based on MOOC
}

\author{
Guoqing DANG ${ }^{1 \text {, a }}$ \\ ${ }^{1,2}$ School of mechanical engineering, XINYU University, XINYU 338031,China \\ a Dangguoqing@126.com
}

Keywords: MOOC, flipped classroom, teaching mode

\begin{abstract}
In recent years, MOOC storm sweeps across higher education all over the world. MOOC, as the collection of high quality curriculum resources, has promoted the knowledge sharing in the world, and created a lot of opportunities for different disciplines of teaching and learning. Flipped classroom, as a kind of inverted classroom for realizing knowledge transference and knowledge internalization by the application of modern technology, is a powerful tool for the interaction between teachers and students and interest stimulation among students, which really reflects "student-centered" education concept and been called the trend of the times "class revolution". If universities choose teaching mode according to their own actual situation, they all will vigorously promote teaching quality of flipped classroom, and give full play to the MOOC in higher education.
\end{abstract}

\section{The introduction of flipped classroom and MOOC}

Traditional teaching mode often is a teacher teaching in the classroom, assign homework to let the students practice at home. This kind one version for all object classes in different levels of students listen to the same curriculum content, neglecting the students individualized learning. It mainly give stress to theory, knowledge but lay less importance on practice and ability, and has the problem of learning and application are disconnected with each other as well as other series of problems. And flipped classroom is upside down of the knowledge and knowledge internalization, turning the traditional classroom teaching structure, making the students learn new knowledge at home by watching video, do their homework, communication, discussion, do project or a new form of teaching, experiment in the classroom. Each student can study according to individual need to set the time and progress before the class, and in the classroom, teachers transfer from traditional content presented to the coach of students, one-on-one communication with students, participate in students seminars, answer questions and be individual guider to improve classroom interaction opportunity.

Flipped classroom effect mainly depends on two areas: one is the students by teachers in advance before class to provide video to learn new knowledge. Video production can attract students? Is convenient for students to watch? Are knowledge system Settings reasonable? Is the interpretation of knowledge deep? Knowledge training and stronger interaction function whether directly affects students' mastery of new knowledge, thus to teachers in the understanding of knowledge system and video production technology has put forward higher requirements, etc. The second is to knowledge internalization by organizing class activities. A variety of classroom activities such as case, project selection, research problems such as process design, class activities organization and the form of direct impact on students' ability of ascension and the understanding of knowledge and internalization. Therefore, the teacher's classroom activity design are also put forward higher requirements. The Internet provides a powerful tool for spreading knowledge and information, MOOC arises at the historic moment. MOOC promoted worldwide share of knowledge content, creates the different disciplines of teaching and learning a lot of opportunities.

MOOC (Massive Open Online Course) originated in 2007, Utah state university professor David Wiley create a network Open courses "type to the Open Education (INST 7150)"based on Wiki. In 2008, the Canadian Dave Cormier and Bryan Alexander proposed the term MOOC, then Canada 
scholars George Siemens and Stephen Downers design the first real MOOC course: Connectives and Connective Knowledge Online Course (CCK08) based on the concept of MOOC. Since May 2013, Beijing university, Tsinghua university, Shanghai Jiaotong university, Fudan university, and many other famous domestic universities have join MOOC. In August 2013, east China normal university jointly the famous high school, Rome middle school and primary school in our country, respectively, formed the C20 MOOC

Alliance (high school), C20 MOOC alliance (middle) and C20 MOOC alliance (primary school), MOOC no longer confined to the field of higher education in China. At present, more and more world famous university professors, scholars begin to pattern design in this course, students from all over the world have caused an upsurge of study MOOC.

\section{The combination of MOOC resources with flipped classroom}

MOOC sets up a network interactive community in addition to providing traditional course materials such as video, reading and problems. Flipped classroom is a pattern of MOOC, both have the characteristics of high identity, complementarity and coupling.

2.1. High quality of MOOC resources MOOC is relying on schools to complete the teaching process, has a relatively complete curriculum structure, such as objective, coordinator, topic, schedules, assignments, etc. Generally speaking, the name of the school curriculum teacher, the micro video, tests, assignments, and the simulation results of design and development and adjustment are done by professional team, can well guarantee the quality of the design and manufacture of the teaching resources, and the high quality "elite schools+ elite teachers + elite class" is just what the flipped classroom needed during students learning and in-class training required before class.

2.2 The convenience usage of MOOC resources MOOC is a kind of free and open form of education, curriculum resources and information to all open and spread through the network, learners without number, the limitation of time, place and tools, its identity certification and the authority of the courses and the function of the registration system is very simple. Student registration later can according to individual need to set the learning schedule, choose their own habits of communication tools such as wikis, blogs, social networking sites such as interactive learning. or can't attend the course timely real-time discussion, can watch the video or record by later to catch up. MOOC openness and personalized learning environment, easy to be used in turn classroom self-study before class, students are easy to be teachers incorporate as important material flip class in-class activities.

2.3 Interactivity of MOOC platform MOOC platform provides an interactive training and machine automatic rating (Auto - grade) and student tracking management, and other functions, these functions can be used to turn the classroom, convenient student class training and immediate feedback, and convenient teachers undertake to the student management, timely grasp the students' learning dynamic, targeted organization class activities.

2.4 Generative and constructive MOOC content MOOC is a kind of emergent curriculum, with dynamic share together, mixing, to adopt, promote the function such as Downers, etc. Teachers by Posting the topic and activities, initial provide only a small amount of learning material, as the starting point of students learning resources and intellectual inquiry; students participate in the discussion topics, activities, thinking and communication, through the "path to look for" and "meaning construction" to construct their own learning and knowledge network, share new resources in the process of communication, new ideas, new ideas, through thinking collisions generate new knowledge, new content, became the center of learning and interaction. Flipped classroom before class online communication, problem of classroom discussion activities also have a generative and constructive, not only can broaden the knowledge field, provide students with endless learning content, and can improve the ability of students to explore new areas and new knowledge. 


\section{The design of teaching mode of flipped classroom based on MOOC}

According to the summarized MOOC operation mode, combining the domestic and foreign typical flip classroom mode, the MOOC video alternative model is shown in the following figure. This pattern is divided into before class and in class two phases:

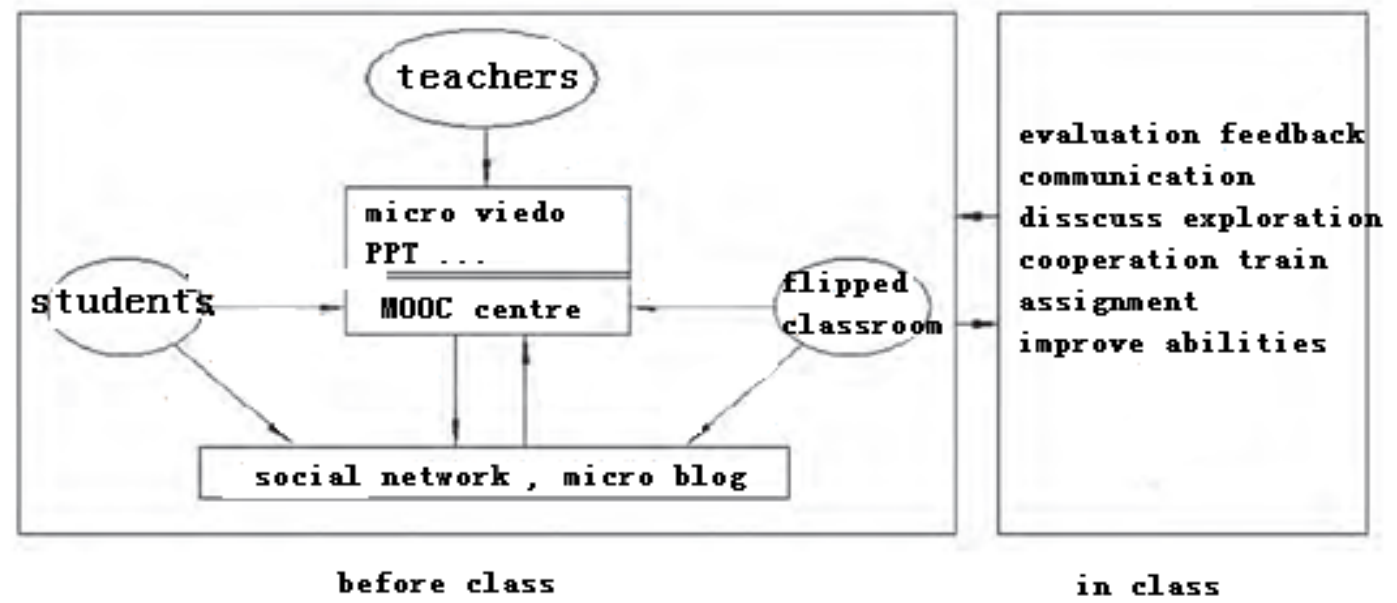

FIG.1: MOOC video teaching

MOOC video alternative model is that students watch the MOOC video before the class instead of teachers making your own video in class, completing MOOC training topic instead of the training of the teachers' own design topic teaching mode to learn new knowledge. Teachers will first of all, the MOOC by course information including profile, curriculum resources, the weekly topic, event notification, the teacher introduced by publishing MOOC center platform, such as by the course coordinator, management and maintenance. MOOC curriculum resources contain mainly knowledge about MOOC micro video, supplemented by MOOC micro courseware, micro case, micro project, micro experiments, such as micro material resources, as well as the MOOC micro "exercise" is given priority to, supplemented by answering questions online, online testing, autonomous learning activities such as online survey feedback of learning. Then, the teacher according to the features of this course, the teaching target and the overall requirement of knowledge system could be divided into several knowledge points, this course is fragmented processing course content, around the fragmentation of knowledge on MOOC platform micro video search for the right course, guiding students to class selectively registration, land for MOOC platform, of course, pay attention to course information, course schedule, the freedom to choose BBS, micro blogging, social networking sites, personalized learning tools such as QQ browse, discussion and communication. Students watch MOOC course micro video according to the requirement of the teacher and a brief training, testing, to complete the new knowledge learning.

The teacher also can register, login MOOC platform of student, browse the curriculum resources, through the MOOC BBS, QQ group, such as tool to communicate with students, timely grasp and solve the problems in students' learning before class. Classroom teachers browse, participate in the process of MOOC course, is both a MOOC ta roles, communication with students and understand the process of the students and guide students, carefully prepared process part in classroom activities. Within the class the students participate in classroom teachers organize class activities to realize knowledge internalization. Flipped classroom is the key to enhance the efficiency of the learning of how to design through class activities which maximize the internalization of knowledge. Design of classroom activities, the teacher should make full use of the situation, cooperation, conversation and give full play to the initiative of the students.

\section{The application of flipped classroom in high schools based on MOOC}

As you can see from the MOOC characteristics, MOOC can effectively make up for the 
inadequacy of flip class: (1) high quality video and interactivity on the MOOC can stimulate students interest in learning; (2) resources on the MOOC platform are come from famous masters, these resources can facilitate teachers making your own video for tilting teaching. At the same time, those teachers can't make a video on their own because of limited conditions also can be directly use video MOOC platforms, so as to save the time available to better organize teaching activities; (3) the establishment of the community on MOOC platform can form the community based on the MOOC can respectively discusses the problems in the community, share ideas so as to improve students' learning interest.

Flipped classroom based on MOOC equally can be divided into knowledge dissemination and knowledge internalization in class before class two parts, the only class of knowledge transmission is carried out through the MOOC. Class knowledge for teachers, there are two situations: (1) the teacher as the MOOC video makers and users; (2) the teacher as the MOOC video users rather than the producer. For both consumers and producers of teachers, it can make full use of the powerful features of the MOOC platform, observed at any time by big data and real-time supervise students' learning, such as supervision, students will read data, whether finished test, etc. At the same time, the teacher through periodic check the achievement of course objectives, can make positive and negative feedback on learners' learning, to understand the effectiveness of the teaching process design, teaching content and method reform, and even can be a fierce debate in the community and students. At the same time, teachers need to use social software such as QQ, sakai, blog set up their own students and exchange platform, and then through the MOOC original questions from other students in the community, and the students' questions according to what you deal in Taichung, targeted in class.

For students, learning before class is also based on the MOOC. Students watch video and do the corresponding exercises according to the teachers' teaching plan, learn step by step according to section. Students can put forward their own problems, and the other students answer each other, or turn to the teachers by watching the video and all kinds of resources. Advanced learning in class with a high degree of interaction can help students internalize knowledge, but also laid the groundwork for classroom teaching.

Flipped classroom makes full use of classroom time to organize effective classroom learning activities, improves the learning efficiency, and maximizes function of student knowledge internalization. Constructivists believe that the process of learners' learning knowledge is realized in certain situations through interpersonal collaboration activities and meaning construction. Therefore, when designing the classroom activities, the teacher should encourage students to do independent exploration, co-operative learning, and make students involved in the specific situation, so as to mobilize students' learning initiative and enthusiasm.

Students, for their part, prepare the material according to the arrangement of the teachers in advance, so can quickly access into the learning in class, from group discussion, interaction between teachers and students to power on to results show, this series of links are to promote the construction of the meaning of knowledge, increase the students' learning motivation. It is a process of migration. For teachers, students need to reflect on learning situation before class and in class participation, answer questions, come to power on and adjust the teaching plan according to the information in a timely manner, improve the teaching method; and for students, they need to reflect on the problems resulting from learning before class and class harvest, so as to promote the understanding of knowledge and construction.

\section{Summary}

Flipped classroom is a kind of brand-new teaching mode, it has won the acceptance of many experts and teachers, but there are also many deficiencies, such as the low quality of teaching resources. Teachers can't supervise the student to study, which causes students to prepare inadequately before class and makes the teacher in class can't make use of time efficiently to let the students learning experience of communication with views collide with each other, cannot achieve good teaching effect. While with the application of MOOC video model, it greatly promotes the interactive 
teaching between teachers and students as well as the interactions between living collaborative learning activities because of the high quality of video and strong interactive communication of teaching objects.

\section{Acknowledgements}

The education of Jiangxi province " 13th Five-Year" ,Project Number: 16 YB166.

\section{References}

[1] Martin, F.G. Will Massive Open Courses Change How We Teach?[J]. Journal of Communications of the ACM, 2012, 55 (8) : 26-28.

[2]Y.Y. Zhang. Reform of teaching mode in the age of MOOC [J]. Journal of university education, 2014, (7) : 49-51.

[3] J.L.Zhang, Y.Wang, B.H.Zhang. Teaching mode research of flipped classroom [J]. Journal of distance education, 2012 (4) : 46-51.

[4] C.L.Bu, Y.Y.Ma. Application feasibility analysis of flipped classroom teaching mode in colleges and universities in our country [J]. Journal of software Tribune, 2013 (7) : 9-11.

[5] X.L.Zhong, S.Q.Song, L.Z.Jiao. Teaching design research based on the concept of flipped classroom under the envorinment of Informatization [J]. Open education research, 2013, (1) : 58-64. [4] J.L.Zhang. The key factors analysis of flipped classroom teaching model [J]. China distance education, 2013 (19) : 59-64. 